\title{
Influence of climate variability on mosquitoes bite in Orlu area of Imo state Nigeria
}

\author{
Fidelis Chinazor Okorie, Cyprain Ezedike \\ Department of Geography and Environmental Management, Imo State University, PMB 2000, Owerri, Imo State, Nigeria
}

\section{Email address:}

chinazorfiddy@hotmail.com (F. C. Okorie)

\section{To cite this article:}

Fidelis Chinazor Okorie, Cyprain Ezedike. Influence of Climate Variability on Mosquitoes Bite in Orlu Area of Imo state Nigeria. Social Sciences. Vol. 3, No. 6, 2014, pp. 183-188. doi: 10.11648/j.ss.20140306.11

\begin{abstract}
Climate change is expected to exacerbate the already serious challenges to human health, food security and economic development, especially in African continent where people are already struggling to meet the challenges posed by existing climate variability. Climate, more especially temperature has a strong and direct influence on development, reproduction and survival of tropic insects such as 'mosquitoes'. Insect population growth potentials are mainly temperature driven, so a rise in temperature may either increase or decrease insect development, likewise rainfall. This paper highlights the rate of mosquitoes bite as evidence by malaria incidence in the study area, which is attributed to the influence of local climate invariability. The study employed the use of 20 years (1991-2010) climate (rainfall and temperature) data of Orlu from Nigerian Meteorological Agency with 20 years data also on malaria cases in Orlu collected from the health centers in the area. Results of the study show variability in the climate of the area, and further reveal that more than $50 \%$ of malaria incidence is caused by temperature increase alone in the area. However, suggestions were made on how to avoid mosquitoes bite and other impacts of climate variability.
\end{abstract}

Keywords: Climate Variations, Mosquitoes, Malaria Incidence, Orlu, Nigeria

\section{Introduction}

Developing countries especially, those in arid, semi-arid and high rainfall regions are more vulnerable to climate variability and change. Nigeria is one of such developing countries and it is well known that Nigerian climate has varied in time and space and it will continue to vary in future. Increased disease vectors, communicable diseases and epidemic are such problems associated with climate variations.

The disease called malaria is caused by protozoa's from the genus plasmodium, which is transmitted from person to person by mosquitoes from the anopheles genus. Scientist however believed that climate is one major determinants of malaria distribution in Africa, largely because both vectors and protozoa prefer warm humid conditions.

Mosquitoes are very sensitive to temperature changes. Warming of their environment within their variable range boots their rate of production, and the number of blood-meals they take prolongs their breeding season and shortens the maturation period for the microbes they disperse.

Malaria is transmitted among humans by female mosquitoes of the genus Anopheles. The spatial distribution intensity of transmission and seasonality of malaria is influenced by climate in sub-Saharan Africa. Malaria is on the increase in the world at large, but particularly in Africa, where climate more especially temperature, has a strong direct influence on reproduction and survival of tropical insects such as mosquitoes. A vectors-borne disease is transmitted by insects (e.g. Mosquitoes) and ticks that is sensitive to temperature, humidity and rainfall.

Mosquitoes are well known as annoying biting pests and vectors of diseases-causing agents to humans and other animals. Hence this research focuses on the rate of mosquitoes bite as evidence by malaria cases, which is attributed to the influence of climate variability in Orlu area of Imo State, Nigeria.

\section{Background Information of the Study Area}

According to geological records, Orlu in Imo State of Southeastern Nigeria is within a sedimentary rock formation and lies within the Awka-Orlu uplands in a zone of sandy 
lateritic soil. It is bounded in the east by Ideato LGA, West by Orsu LGA, North by Anambra State and South by Njaba LGA (see fig. 1). It has a population of 143,17 persons (National Population commission, 2006). The climate is a typical humid climate, the same in the southeastern region of Nigeria. Two distinctive seasons are familiar with the climate of the area. The rainy season that begins in April and ends in October, with higher intensity in June and July and late September and dry season which begins in November and ends in March. The annual amounts of rainfall vary between $1,990 \mathrm{~mm}$ and $2,200 \mathrm{~mm}$. Temperature characterizes are generally high with little variations during the year. The mean daily maximum air temperature ranges from $230 \mathrm{C}$ $280 \mathrm{C}$, while the mean daily minimum values rang from 200C-260C. This shows that Orlu receives abundant relatively constant solar radiation because of its latitudinal location being bisected by the 50 parallel.

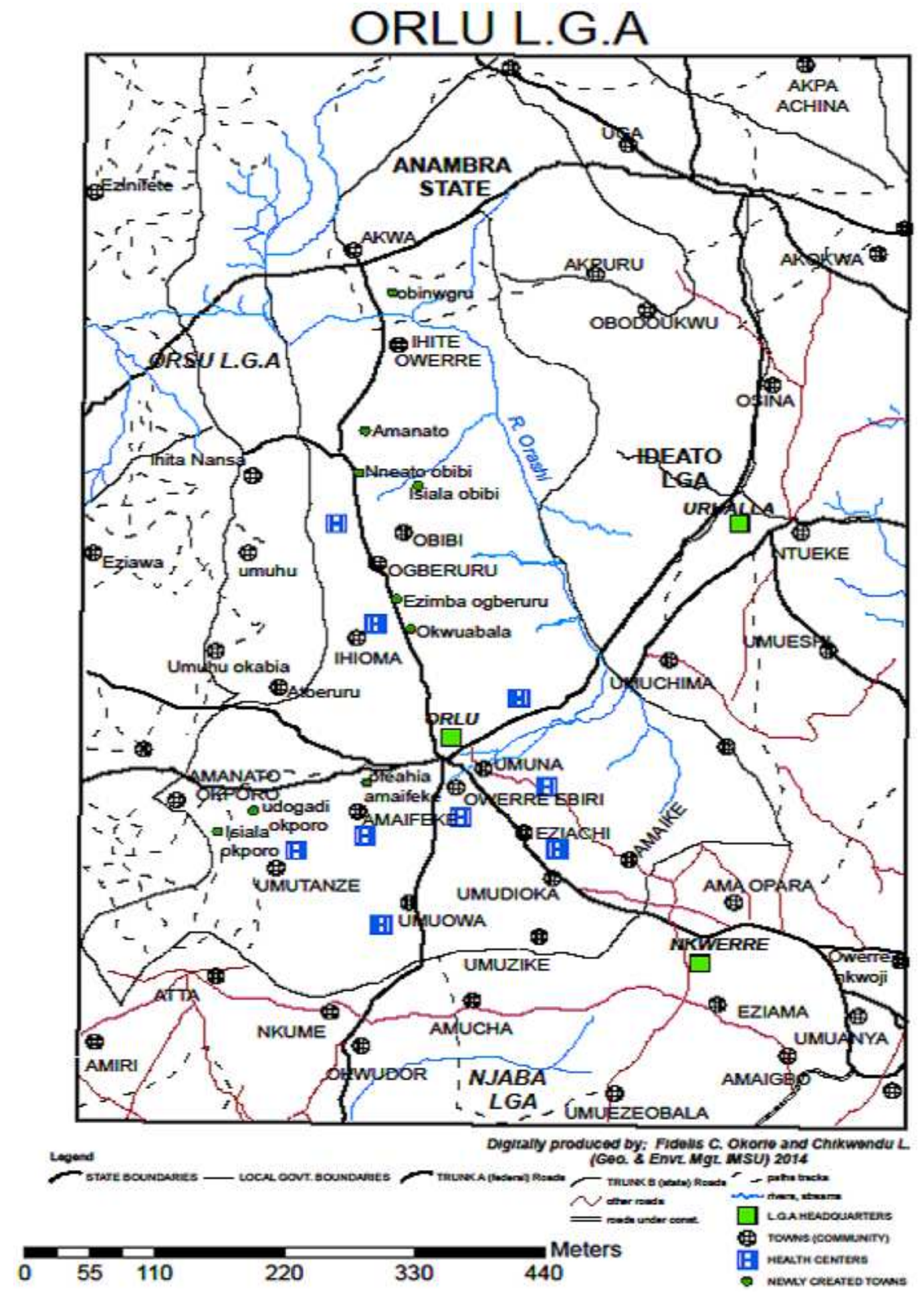

Figure 1. Map of Orlu in Imo State, Nigeria. 


\section{Materials and Methods}

Twenty years (i.e. from 1991-2010) rainfall and temperature are data of Orlu, acquired from Nigerian Meteorological Agency, Lagos was used. The weather data is being recorded at the synoptic station in Owerri (the state capital) and the data is covering the entire Imo State. Also, data on malaria cases collected from nine (9) different health centers located within Orlu was used. Health centers in Orlu include Government Maternity in Umuna, Eziachi Health Centers, Owerri-Ebiri Health center, Okwuabala (in Ihioma) health center, Umuowa Health center, Umutanze health center, Acharaba Health center in Ogberuru, Ndiowa Health center in Orlu Urban and Model primary Healthcare center in Ofeahia (Amaifeke) (see figure 1 above). The data on malaria cases for the same period (1991-2010) was collected from Roll-back Malaria Department of Imo State Ministry of Health, Orlu area office. The weather data (rainfall and temperature) were put together to determine first, the extent of variability in the climate system of the area, and both the weather data and malaria cases data were put together to draw a correlation between the climate factors (rainfall and temperature) and the health factors (malaria cases) caused by mosquitoes bite (see table 1\&2).

Table 1. Rainfall, Temperature and Malaria Cases Data of Orlu (1991-2010).

\begin{tabular}{|c|c|c|c|c|c|c|c|}
\hline $\mathbf{S} / \mathbf{N}$ & Year & Total RF (mm) & Mean Annual. RF (mm) & Mean Max. Temp (0 C) & Mean Min. Temp. (0C) & Average Temp. (0C) & Average Malaria cases \\
\hline 1 & 1991 & 2567.4 & 210.6 & 31.6 & 23.5 & 28.0 & 305 \\
\hline 2 & 1992 & 2424.1 & 202 & 31.7 & 22.9 & 27.3 & 300 \\
\hline 3 & 1993 & 2182.8 & 181.9 & 31.7 & 23.0 & 27.4 & 362 \\
\hline 4 & 1994 & 2626 & 219 & 31.8 & 22.3 & 27.1 & 335 \\
\hline 5 & 1995 & 2622.3 & 219 & 31.9 & 22.4 & 27.2 & 377 \\
\hline 6 & 1996 & 2705.5 & 225 & 32.5 & 23.0 & 28.0 & 375 \\
\hline 7 & 1997 & 2891.4 & 241 & 32.3 & 23.5 & 28.0 & 359 \\
\hline 8 & 1998 & 1640.1 & 136 & 31.1 & 23.6 & 28.4 & 373 \\
\hline 9 & 1999 & 2515.4 & 209.6 & 31.8 & 23.7 & 28.0 & 382 \\
\hline 10 & 2000 & 2337.2 & 195 & 32.2 & 23.6 & 28.0 & 356 \\
\hline 11 & 2001 & 2304.3 & 192 & 32.3 & 23.8 & 28.1 & 324 \\
\hline 12 & 2002 & 2053.7 & 171 & 32.3 & 23.7 & 28.0 & 360 \\
\hline 13 & 2003 & 2327.8 & 194 & 32.4 & 24.1 & 28.3 & 360 \\
\hline 14 & 2004 & 1762.3 & 147 & 32.4 & 28.9 & 30.7 & 363 \\
\hline 15 & 2005 & 2336.6 & 186.4 & 23.8 & 24.1 & 29.0 & 379 \\
\hline 16 & 2006 & 3209.1 & 267 & 32.9 & 24.3 & 29.0 & 367 \\
\hline 17 & 2007 & 2361.6 & 197 & 31.7 & 22.2 & 27.0 & 358 \\
\hline 18 & 2008 & 2470.2 & 205.9 & 32.7 & 23. & 28.2 & 361 \\
\hline 19 & 2009 & 2092.8 & 174.4 & 31.5 & 22.7 & 27.1 & 347 \\
\hline 20 & 2010 & 2651.6 & 221 & 31.7 & 23.2 & 27.5 & 591 \\
\hline
\end{tabular}

Source of Data: Nigerian Meteorological Agency (NIMET) Lagos 2011, and Ministry of Health, Orlu Health Centre, Imo State, 2013.

Table 2. Statistical table for computing correlation between $X$ and $Y$.

\begin{tabular}{|c|c|c|c|c|c|c|c|}
\hline X1 & $\mathbf{X} 2$ & $\mathbf{Y}$ & $\mathrm{X} 12$ & $\mathrm{X} 22$ & Y2 & X1Y & $\mathrm{X} 2 \mathrm{Y}$ \\
\hline 201.6 & 28 & 305 & 40642.6 & 784 & 93,025 & 61,488 & 8,540 \\
\hline 202 & 27.3 & 300 & 40,8021 & 745.3 & 90,000 & 60,600 & 8,190 \\
\hline 181.9 & 27.4 & 362 & $33,087.6$ & 750.8 & 131,044 & 65,848 & 9,919 \\
\hline 219 & 27.1 & 335 & 47,961 & 734.4 & 112,225 & 73,365 & 9,079 \\
\hline 219 & 27.2 & 377 & 47,961 & 739.8 & 142,129 & 82,563 & 10,254 \\
\hline 225 & 28 & 375 & 50,625 & 784 & 140,625 & 84,375 & 10,500 \\
\hline 241 & 28 & 359 & 58,081 & 784 & 128,881 & 86,519 & 10,052 \\
\hline 209.6 & 28 & 382 & $43,932.2$ & 784 & 145,924 & 80,067 & 10,696 \\
\hline 195 & 28 & 356 & 38,025 & 784 & 126,736 & 69,420 & 9,968 \\
\hline 192 & 28.1 & 324 & 36,864 & 789.6 & 104,976 & 62,208 & 9,104 \\
\hline 171 & 28 & 360 & 29,241 & 784 & 129,600 & 61,560 & 10,080 \\
\hline 194 & 28.3 & 360 & 37,636 & 800.9 & 129,600 & 69,840 & 10,188 \\
\hline 147 & 30.7 & 363 & 21,609 & 942.5 & 131,769 & 53,361 & 11,144 \\
\hline 186.4 & 29 & 379 & 34.745 & 841 & 143,641 & 70,646 & 10,991 \\
\hline 205.9 & 28.2 & 361 & $42,394.8$ & 795.2 & 130,321 & 74,330 & 10,180 \\
\hline 174.4 & 27.1 & 347 & $30,415.4$ & 734.4 & 120,409 & 60,517 & 9,404 \\
\hline 221 & 27.5 & 591 & 48,841 & 756.3 & 349,281 & 130,611 & 16,253 \\
\hline $3,985.8$ & 560.3 & 7,334 & $811,459.6$ & $15,710.8$ & $2,761,168$ & $1,466,561$ & 205,444 \\
\hline
\end{tabular}




\section{Results and Discussion}

\subsection{Correlation Analysis Using Pearson's Product Moment Correlation Coefficient}

$\mathrm{X}$ is a climatic factors (Rainfall and Temperature) i.e. $\mathrm{X} 1=$ Rainfall and X2= Temperature, being independent variables while the value of Y (Malaria cases) is a health factor and a dependent variable.

Therefore $\mathrm{Y}$ is dependent on $\mathrm{X}$

Formulae for computing the Pearson's Correlation Coefficient is

$$
r=\frac{\sum x y-\frac{\sum x \sum y}{N}}{\sqrt{\left(\sum x^{2}-\frac{\left(\sum x\right)^{2}}{N}\left(\sum y^{2}-\frac{\left(\sum y\right)^{2}}{N}\right)\right.}}
$$

Where $\mathrm{N}=$ number of years $=20$

Therefore for rainfall variation X1 and Malaria Cases Y

$$
\begin{gathered}
r=\frac{1466561-\frac{3985.8 \times 7334}{20}}{\sqrt{\left(811459.6-\frac{(3985.8)^{2}}{20}\right)\left(2761168-\frac{(7334)^{2}}{20}\right)}} \\
r=\frac{1466561-1461593}{\sqrt{(811459.6-794330)(2761168-2689377.8)}} \\
r=\frac{4968}{\sqrt{304,735,684}} \\
r=0.285 ; r^{2}=0.0812 \\
1-0.0812=0.9138 \times 100=91.88 \%
\end{gathered}
$$

The value of $r=0.285$ indicates a strong positive correlation between rainfall variation and malaria cases in Orlu. This implies that $91.88 \%$ of malaria incidence induced by mosquitoes bite in Orlu area can be attributed to variation in rainfall.

For temperature regime X2 and Malaria Cases

$$
\begin{gathered}
r=\frac{205444-\frac{560.3 \times 7334}{20}}{\sqrt{\left(15710.8-\frac{(560.3)^{2}}{20}\right)\left(2761168-\frac{(7334)^{2}}{20}\right)}} \\
r=\frac{205444-205462.01}{\sqrt{(15710.8-15696.8)(2761168-2.689377 .8)}} \\
r=\frac{-18}{\sqrt{1005.060}} \\
1-0.00032=0.999 \times 100=99.97 \%
\end{gathered}
$$

The value of $\mathrm{r}=-0.0179$ also indicates a very strong positive correlation between temperature regime and malaria incidence in Orlu. This implies that about 99.97\% (almost $100 \%$ ) of malaria cases induced by mosquitoes bite in Orlu area can be attributed to temperature regime; hence high temperatures influence breeding, growth and survival of mosquitoes.

\subsection{Discussion}

The study established that there is variability in the climate systems of the area based on Local and regional climate variations. For example, mean annual rainfall of the area varies from $201.6 \mathrm{~mm}$ in 1991 to $202 \mathrm{~mm}$ in 1992, from $181.9 \mathrm{~mm}$ in 1993 to $219 \mathrm{~mm}$ in $1994 / 1995$. From $136 \mathrm{~mm}$ (the least) in 1998 to $209.6 \mathrm{~mm}$ in 1999 , from $267 \mathrm{~mm}$ (the highest) in 2006 to $197 \mathrm{~mm}$ in 2007 , and from $174.4 \mathrm{~mm}$ in 2009 to $221 \mathrm{~mm}$ in 2010 . Average temperature on the other hand was $280 \mathrm{C}$ in $1991,27.30 \mathrm{C}$, in $1992,27.10 \mathrm{C}$, in 1994 , $28.40 \mathrm{C}$, in 1998 and $30.70 \mathrm{C}$ (the highest) in $2004,270 \mathrm{C}$ (the least) in 2007, 28.20C, in 2008, and 27.50C in 2010 (see figure 2 below).

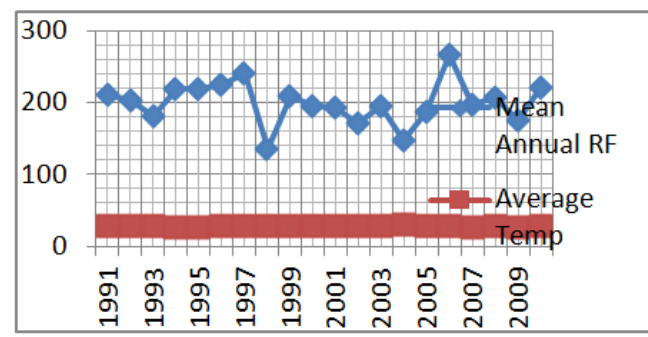

Figure 2. Graphical representation of 20 years Rainfall and Temperature condition of Orlu.

From the correlation analysis, the value of $r$ for $\mathrm{X} 1$ indicates a strong positive correlation between rainfall variability and malaria cases in Orlu. This implies that $91.88 \%$ of malaria cases in the area can be attributed to rainfall variability. Also the value of $r$ for X2 shows a very strong positive correlation which implies that $99.97 \%$ of malaria incidence in the area can be attributed to increase in temperature. So, on the average, about $95.9 \%$ of malaria cases induced by mosquitoes bite in Orlu area of Imo State is influenced by the variations in climate system of the area. For example in 1991 rainfall was $210.6 \mathrm{~mm}$ and temperature, $280 \mathrm{C}$ with malaria cases 305 . In 1996, rainfall increased to $225 \mathrm{~mm}$ and temperature remained stable at $28 \mathrm{oC}$ but malaria cases increased to 375 . In 1999 rainfall was $209.6 \mathrm{~mm}$ and temperature remained at $280 \mathrm{C}$ while malaria cases increased to 382. In 2005, rainfall declined to $186.4 \mathrm{~mm}$ and temperature increased more to $290 \mathrm{C}$ while malaria cases remained high at 379 . In the last year (2010), rainfall was a bit high with $221 \mathrm{~mm}$ and the temperature was still high though decreased to $27.5 \mathrm{oC}$ while malaria cases increased sharply to 591 (see figure 3 below). 


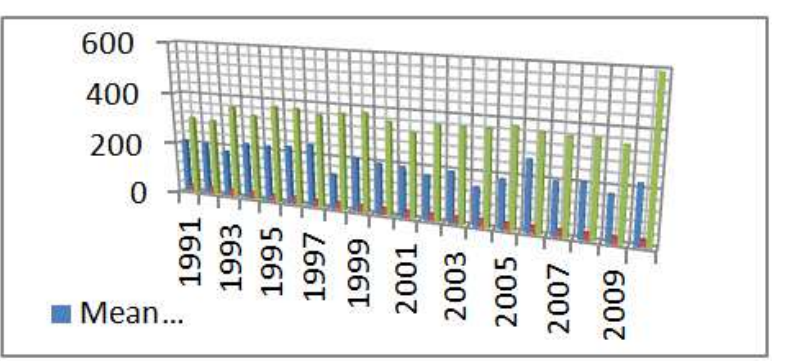

Figure 3. A histogram showing correlation between climate factors (rainfall and temperature) and health factor (malaria case)

\section{Conclusion}

\subsection{Consequences of Weather and Climate Variability for People's Daily Lives in Orlu}

Weather and climate affects people's daily livelihoods in Orlu as the case in many other parts of world. Steady high temperature conditions in the area makes people in their offices, at homes and in market places and workshops feel uncomfortable, especially from 12 noon to 12 midnight. This is due to high insolation (solar energy) from the sun reaching the atmosphere and the earth surface daily. Net radiation (both the incoming ultraviolet and outgoing infra-red radiations) makes the environment to be constantly warmer, hence "global warming". Many people, (youths and children) in particular run down to nearby streams and rivers to swim at hot afternoons. Some people at homes and offices take shade under trees, while most windows and doors at home and offices are kept open always under such high temperature conditions. At nights also, many people can keep their doors and windows wide open when sleeping, and some others may sleep outside for a long time before getting into their bedrooms. This as a result exposes many people to annoying biting pests and vectors of disease like "mosquitoes".

\subsection{Impact of Mosquitoes Bites on Livelihoods and Behavior of People in their Daily Lives}

Behavioral attitude of people can change daily and life of people affected due to the influence of weather. Bites from mosquitoes carrying certain viruses or parasites can cause severe illness. Infected mosquitoes in many parts of the world transmit West Nile Virus to humans. Other mosquitoborne infections include yellow fever, dengue fever, malaria and some types of brain infection (encephalitis).

This study has identified rainfall and temperature as climatic factors that are possibly influencing the breeding and biting of mosquitoes in Orlu, thus spreading of malaria that causes many deaths in the area.

Generally, mosquitoes transmit diseases to over 700 million people per year (WHO, 2007). Snow, (2005) indicated that about $90 \%$ of malaria related deaths occur in sub-Saharan Africa. Mosquito bites cause severe illness to humans including malaria, yellow fever, encephalitis (West Nile), dengue fever, epidemic polyarthritis (Rose River virus), and filiariasis. "These diseases frequently cause serious discomfort to people and therefore affect their lives and behavior. How can people behave rational, think positively, or even live healthy daily with some health challenges such as fever chills, headache, joint and muscle pain, nausea, vomiting and diarrhea, convulsion, bleeding into the skin, sensitivity to light, weakness and seizures, severe dizziness, rash and even elephantiasis. These health challenges induced by mosquito bite that affect people's daily livelihoods and behavior have been identified in this research as a consequence of changes in weather and climate. Hence, people with such health conditions cannot go to work, could hardly attend to clients and customers and to carry out domestic duties would be impossible.

\section{Recommendations}

Since this research has established that climate variability can enhance mosquitoes' bite which can transmit malaria to humans, the authors therefore recommend as follows:

1. Malaria kills, so people should kill mosquitoes and use mosquito nets always for prevention.

2. The inhabitants of Orlu should frequently keep their surroundings clean because dirty environment encourages breeding of mosquitoes.

3. Waste materials should always be disposed of appropriately.

4. People should plant trees and flowers around their homes and offices which can absorb parts of solar radiation and thus reduce the effect of global warming within the environment

5. The government laws and policies to maintain sanitary conditions and protect the environment should be strictly adhered to.

6. Drainage channels and gutters for movement of floods and rainfall runoff should be maintained properly.

\section{Acknowledgements}

The authors appreciate the Nigeria TETfund and Imo State University for making fund available for this research to be presented at the AAG Conference in the US.

\section{References}

[1] Adefolalu, O.O. (2007). "Climate Change and Economic Sustainability in Nigeria". Paper presented at the International Conference on Climate Change and Economic Sustainability. Nnamdi Azikiwe University, Enugu Nigeria, June 12-14 2007.

[2] IPCC (2007). Impacts, Adaptations and Mitigation of Climate Contribution of Working Group, 11 to the Second assessment of the IPCC. Cambridge University Press, 367: 1792-1798

[3] National Population Commission (2006). Population census of the federal Republic of Nigeria, Abuja.

[4] NIMET (Nigeria Meteorological Agency), (2008). Climate, Weather and Water information for sustainable development and safety. 
[5] Nwafor, J.C. (2007). Global Climate Change: the driver of multiple causes of flood intensity in sub-Saharan Africa. Paper presented at the International Conference on Climate Change and Economic Sustainability. Nnamdi Azikiwe University, Enugu Nigeria, June 12-14 2007.

[6] Okorie F.C., Okeke, I.C., Njoku J.D., Duru, P.N. (2012),Climate variability and malaria incidence: Impact and Adaptation in Owerri Municipal of Imo State Nigeria, Advances in Education Research. November 2012, San Degio, CA USA, pp 98-104.

[7] Randall, (2007), Malaria risk and temperature: influences from global climate change and local land use practices. Proc Wat'L, Acad.Sci USA, 103:5635-5636
[8] Snow, R.W., (2005). Climate change: regional warming and malaria resurgence: nature 2005, 420: 627-628.

[9] UNICEF, (2009). The rise and fall of Malaria in Europe. A historical - epidemiological study. Oxford: Oxford University, 15: $105-111$

[10] National Population Commission, (2006). Population census of the Federal Republic of Nigeria, Abuja

[11] WHO (1995). Climate change and health: global to local influences on disease risk; Ann Trop Med Parasitol, 100; 535549. 